Research Article

\title{
Genetic variation in cultivated Rheum tanguticum populations
}

\author{
Yanping $\mathrm{Hu}^{1}$, Xiaolong Xie ${ }^{2}$, Li Wang ${ }^{1}$, Huaigang Zhang ${ }^{1}$, Jian Yang ${ }^{1}$ and $\mathrm{Yi} \mathrm{Li}^{1}$ \\ ${ }^{1}$ Northwest Institute of Plateau Biology, the Chinese Academy of Sciences, Xining, China. \\ ${ }^{2}$ School of Pharmacy, Henan University of Traditional Chinese Medicine, Zhengzhou, China.
}

\begin{abstract}
To examine whether cultivation reduced genetic variation in the important Chinese medicinal plant Rheum tanguticum, the levels and distribution of genetic variation were investigated using ISSR markers. Fifty-eight $R$. tanguticum individuals from five cultivated populations were studied. Thirteen primers were used and a total of 320 DNA bands were scored. High levels of genetic diversity were detected in cultivated $R$. tanguticum $(P P B=82.19$, $H=0.2498, H_{B}=0.3231, I=0.3812$ ) and could be explained by the outcrossing system, as well as long-lived and human-mediated seed exchanges. Analysis of molecular variance (AMOVA) showed that more genetic variation was found within populations $(76.1 \%)$ than among them $(23.9 \%)$. This was supported by the coefficient of gene differentiation $\left(G_{s t}=0.2742\right)$ and Bayesian analysis $\left(\theta_{B}=0.1963\right)$. The Mantel test revealed no significant correlation between genetic and geographic distances among populations $(r=0.1176, p=0.3686)$. UPGMA showed that the five cultivated populations were separated into three clusters, which was in good accordance with the results provided by the Bayesian software STRUCTURE $(K=3)$. A short domestication history and no artificial selection may be an effective way of maintaining and conserving the gene pools of wild $R$. tanguticum.
\end{abstract}

Keywords: cultivated populations, genetic variation, ISSR, Polygonaceae, Rheum tanguticum Maxim. ex Balf.

Received: November 26, 2013; Accepted: May 12, 2014.

\section{Introduction}

Rheum tanguticum Maxim. ex Balf. (Dahuang in Chinese) is an endangered perennial herbaceous plant endemic to China, with a distribution mainly in Qinghai, Gansu Provinces and west Tibetan Autonomous Region at altitudes of 2,300-4,200 m above sea level; this plant is found along forest edges and in valleys (Yang, 1991; Liu, 1997; Li, 2003; Wang and Ren, 2009). The roots and rhizomes of this plant officially listed in the Chinese Pharmacopoeia have been used in traditional medicine for over 2,000 years to treat various syndromes caused by circulatory problems (e.g., dysmenorrhoea, hypermenorrhea, hematemesis, lower abdominal pain, etc), jaundice, diarrhea and constipation (Yang, 1991; Komatsu et al., 2006; Li et al., 2006; Chinese Pharmacopoeia Commission, 2010).

As a result of over-harvesting and destruction of its habitat by humans in recent decades, natural populations of R. tanguticum have declined dramatically (Hu et al., 2010; Wang, 2010). This led to $R$. tanguticum being listed as a key protected plant of Qinghai Province by the government in 2009 (The People's Government of Qinghai Province, 2009). The breeding system of $R$. tanguticum is outcrossing, with pollination probably involving wind and insects

Send correspondence to Yi Li. Northwest Institute of Plateau Biology, the Chinese Academy of Sciences, 23 Xinning Road, 810008, Xining, China. E-mail: liyi@nwipb.cas.cn.
(Chen et al., 2009). Large panicles produce many winged seeds that are dispersed by wind. The seed set and germination rates of R. tanguticum are very high (Xie X (2009) $\mathrm{PhD}$ thesis, Graduate University of the Chinese Academy of Sciences, Xining).

Since the 1960s, R. tanguticum has been extensively cultivated in its original area of production (Qinghai Province). The species is propagated predominantly by sexual reproduction involving seeds. Farmers usually randomly collect mature seeds directly from wild populations in local or distant areas, mix them together, and plant them in the fields. Sometimes, the seeds are exchanged with relatives or friends, an activity that disperses the germplasm to other places. To date, most studies of $R$. tanguticum have focused on cultivation, tissue culture and analysis of the plant's chemical constituents (Zhang, 2004; Che et al., 2006; VanMen et al., 2012). Although previous reports have provided preliminary assessments of the genetic diversity of wild $R$. tanguticum (Chen et al., 2009; Hu et al., 2010; Wang et al., 2012b), there has been no report on the genetic diversity of cultivated populations.

Inter-simple sequence repeats (ISSR) are molecular markers with primers designed based on repeat motifs (microsatellites) of eukaryotic genomes that require no prior knowledge of DNA sequence (Zietkiewicz et al., 1994). These markers have good stability and large polymorphism. In recent years, ISSR has been successfully 
used to investigate the genetic diversity and relationships at species, population and cultivar levels in many plants, including some medicinal species (Tacuatia et al., 2012; Chen et al., 2013; Kumchai et al., 2013; Thriveni et al., 2013; Verma and Rana, 2013). In this study, we used ISSR markers to: (1) detect the level of genetic diversity and structure in five cultivated populations and (2) evaluate the possible impact of cultivation practices on the genetic diversity of $R$. tanguticum. The results obtained should be useful in developing strategies for efficient management of the genetic resources of $R$. tanguticum and for future breeding programs.

\section{Materials and Methods}

\section{Plant materials}

Fifty-eight individuals of $R$. tanguticum were sampled from five cultivated populations in Qinghai Province, China (Figure 1). Each population was positioned by GPS, with the location details listed in Table 1. Young leaf tissues were collected from individual plants located at least $10 \mathrm{~m}$ apart and then dried in silica gel. All of the material collected was identified by Dr. Xuefeng Lu and voucher specimens were deposited in the Qinghai-Tibetan Plateau Museum of Biology, Northwest Institute of Plateau Biology, Chinese Academy of Sciences.

\section{DNA extraction and ISSR amplification}

Genomic DNA was extracted using the modified cetyltrimethylammonium bromide (CTAB) method described by Doyle and Doyle (1987). The DNA concentration was determined by comparing the sample with known standards of lambda DNA in $0.8 \%(\mathrm{w} / \mathrm{v})$ agarose gels. The isolated genomic DNA was diluted to $30 \mathrm{ng} / \mu \mathrm{L}$ and stored at $-20{ }^{\circ} \mathrm{C}$ until ISSR amplification.

One hundred primers from the University of British Columbia (UBC set no. 9) were initially screened for PCR amplification and 13 primers that produced clear, reproducible banding patterns were chosen for final analysis (Table 2). PCR amplifications were done in a $20 \mu \mathrm{L}$ reaction volume consisting of $30 \mathrm{ng}$ of genomic DNA, $3.0 \mathrm{mM}$ $\mathrm{MgCl}_{2}, 0.1 \mathrm{mM}$ dNTP, 10 pmol of primer, $0.75 \mathrm{U}$ of Taq DNA polymerase (TaKaRa Biotech Co., Ltd.) and $2.0 \mu \mathrm{L}$ of 10 PCR buffer. ISSR-PCR amplifications were done in a PTC-221 thermocycler (MJ Research, Bio-Rad, USA) using the following program: an initial step of $5 \mathrm{~min}$ at $94{ }^{\circ} \mathrm{C}$ followed by $20 \mathrm{~s}$ at $94^{\circ} \mathrm{C}, 60 \mathrm{~s}$ at the appropriate annealing temperature (see Table 2 for details) and $80 \mathrm{~s}$ at $72{ }^{\circ} \mathrm{C}$ for 38 cycles, with a final extension of $6 \mathrm{~min}$ at $72^{\circ} \mathrm{C}$. The negative control consisted of replacing template DNA with $\mathrm{ddH}_{2} \mathrm{O}$ to test for contamination. The amplification products were separated in $1.5 \%$ agarose gels stained with ethidium bromide and photographed with a GDP-8000 System (UVP Inc., USA). Molecular weights were estimated using a 200 bp DNA ladder (TaKaRa Biotech Co., Ltd.).

\section{Data analysis}

Only unambiguously and reproducibly amplified ISSR bands were scored as present (1) or absent (0). Smeared and weak bands were excluded. The resulting binary data matrix was analyzed using POPGENE version 1.32 (Yeh et al., 1999) to estimate the level of genetic diversity under the assumption of Hardy-Weinberg equilibrium. Genetic diversity parameters, including the percentage of polymorphic bands (PPB), the gene diversity

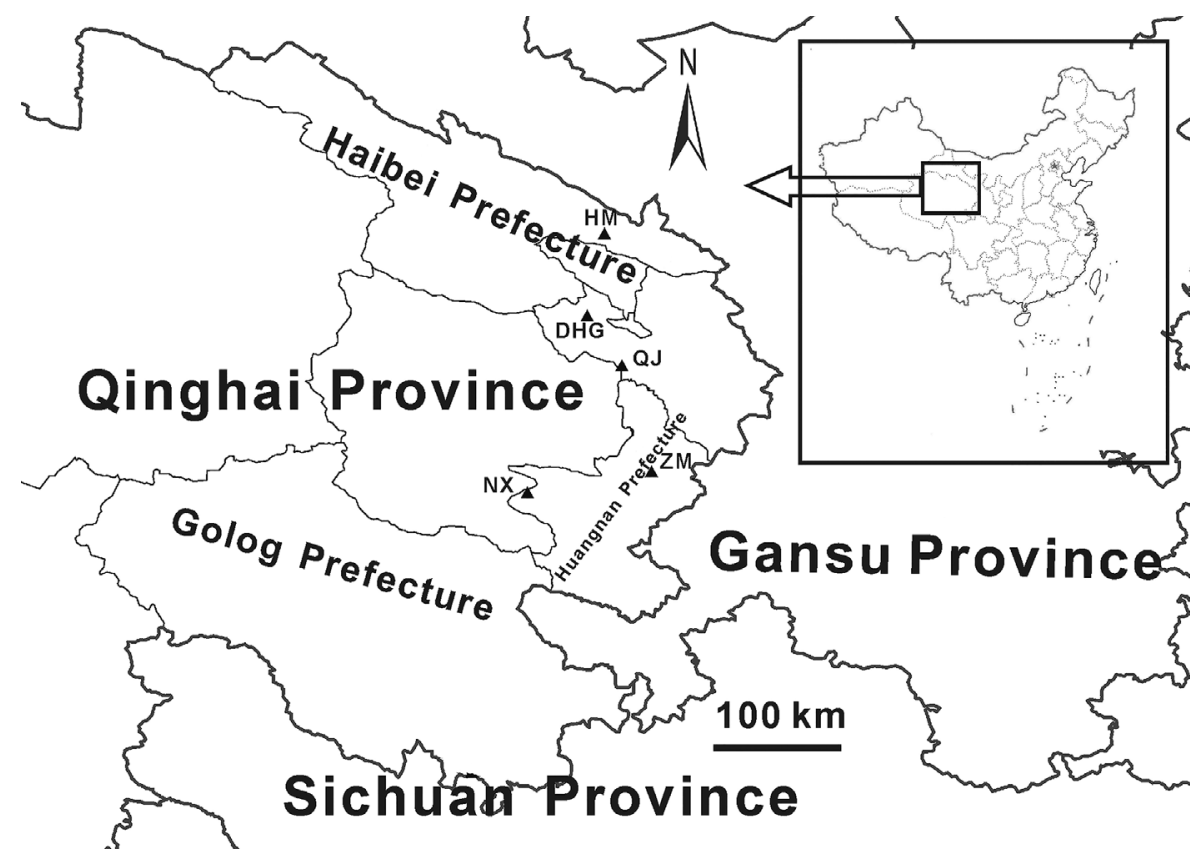

Figure 1 - Locations of the five $R$. tanguticum populations sampled from Qinghai Province in this study. 
Table 1 - Sample information for the five cultivated populations of $R$. tanguticum used in this study.

\begin{tabular}{|c|c|c|c|c|c|c|}
\hline Population & Locality & Longitude (E) & Latitude $(\mathrm{N})$ & Sample size & Vouchers & Altitude (m) \\
\hline $\mathrm{HM}$ & Haomen, Menyuan county, Haibei Prefecture & $100^{\circ} 31^{\prime} 15.2 ”$ & $37^{\circ} 26^{\prime} 13.3^{\prime \prime}$ & 13 & 2006091611 & 2,997 \\
\hline $\mathrm{NX}$ & Ningxiu, Zeku county, Huangnan Prefecture & $100^{\circ} 51^{\prime} 6.4^{\prime \prime}$ & $35^{\circ} 11^{\prime} 27.3^{\prime \prime}$ & 11 & 2006091812 & 3,352 \\
\hline $\mathrm{ZM}$ & Zhamao, Tongren county, Huangnan Prefecture & $101^{\circ} 55^{\prime} 46.3^{\prime \prime}$ & $35^{\circ} 22^{\prime} 23.6^{\prime \prime}$ & 7 & 2006092115 & 3,099 \\
\hline DHG & Daheigou, Huangyuan county, Xining City & $101^{\circ} 22^{\prime} 18.3^{\prime \prime}$ & $36^{\circ} 43^{\prime} 29.8^{\prime \prime}$ & 14 & 2006092516 & 2,897 \\
\hline QJ & Qunjia, Huangzhong county, Xining city & $101^{\circ} 40^{\prime} 25.3^{\prime \prime}$ & $36^{\circ} 17^{\prime} 30.7^{\prime \prime}$ & 13 & 2006092617 & 2,818 \\
\hline
\end{tabular}

Table 2 - Primers used for ISSR amplification and bands amplified in all individuals sampled.

\begin{tabular}{lcccc}
\hline Primers & $\begin{array}{c}\text { Sequence 5, } \\
\rightarrow 3\end{array}$ & $\mathrm{~T}_{\mathrm{m}}\left({ }^{\circ} \mathrm{C}\right)$ & $\begin{array}{c}\text { No. of bands } \\
\text { studied }\end{array}$ & $\begin{array}{c}\text { No. of polymorphic } \\
\text { bands }\end{array}$ \\
\hline 809 & $(\mathrm{AT})_{8} \mathrm{~T}$ & 53.2 & 23 & 20 \\
811 & $(\mathrm{GA})_{8} \mathrm{C}$ & 52.5 & 24 & 20 \\
825 & $(\mathrm{AC})_{8} \mathrm{~T}$ & 52.0 & 27 & 25 \\
834 & $(\mathrm{AG})_{8} \mathrm{YT}$ & 53.0 & 29 & 24 \\
836 & $(\mathrm{AG})_{8} \mathrm{YA}$ & 53.0 & 22 & 20 \\
840 & $(\mathrm{GA})_{8} \mathrm{YT}$ & 51.0 & 24 & 18 \\
841 & $(\mathrm{GA})_{8} \mathrm{YC}$ & 53.2 & 23 & 21 \\
842 & $(\mathrm{GA})_{8} \mathrm{YG}$ & 53.2 & 24 & 20 \\
868 & $(\mathrm{GAA})_{6}$ & 51.2 & 25 & 20 \\
888 & $\mathrm{BDB}(\mathrm{CA})_{7}$ & 58.5 & 25 & 19 \\
889 & $\mathrm{DBD}(\mathrm{AC})_{7}$ & 55.0 & 25 & 17 \\
890 & $\mathrm{VHV}(\mathrm{GT})_{7}$ & 59.0 & 23 & 21 \\
891 & $\mathrm{HVH}(\mathrm{TG})_{7}$ & 56.2 & 26 & 18 \\
Total & & & 320 & 263 \\
\hline
\end{tabular}

$\mathrm{Y}=(\mathrm{C}, \mathrm{T}) ; \mathrm{B}=(\mathrm{C}, \mathrm{G}, \mathrm{T}) ; \mathrm{D}=(\mathrm{A}, \mathrm{G}, \mathrm{T}) ; \mathrm{H}=(\mathrm{A}, \mathrm{G}, \mathrm{T}) ; \mathrm{V}=(\mathrm{A}, \mathrm{C}, \mathrm{G})$.

index $H$ (Nei, 1973) and Shannon's information index $(I)$, were obtained at the species and population levels. Gene differentiation between populations was estimated by the coefficient of gene differentiation $\left(G_{s t}\right)$ and gene flow $\left(N_{m}\right.$, the numbers of migrants per generation) was calculated from $G_{s t}$ according to McDermott and McDonald (1993), where $N_{m}=0.5\left(1-G_{s t}\right) / G_{s t}$. To examine the genetic relationship among populations, unbiased genetic distance and genetic identity (Nei, 1978) were also calculated for all pairwise combinations of populations by POPGENE and a dendrogram was constructed from Nei's genetic distance with the unweighted pair-group method of averages (UPGMA) using NTSYSpc software (Rohlf, 2000).

To correct for possible bias introduced by the assumption of Hardy-Weinberg equilibrium, Bayesian gene diversity $\left(H_{B}\right)$ and population differentiation $\left(\theta_{B}\right)$ were also calculated by the Bayesian approach (Holsinger et al., 2002) using HICKORY, version 1.1 (Holsinger and Lewis, 2003). The Bayesian method does not assume HardyWeinberg equilibrium within populations and does not treat multilocus ISSR phenotypes as haplotypes, but takes full advantage of the information provided by dominant markers. This allows the incorporation of uncertainty regarding the magnitude of the within-population inbreeding coefficient into estimates of $F_{s t}$ (Holsinger and Wallace, 2004; Zhang et al., 2007). Several runs were done with default sample parameters (burn-in $=5000$, sample $=$ 100000 , thin $=20$ ) to ensure consistency of the results (Tero et al., 2003). Model selection was based on the Deviance Information Criterion (DIC) (Spiegelhalter et al., 2002) in which models with smaller DICs are preferred (Holsinger and Lewis, 2003).

An additional measurement for partitioning genetic variation was obtained with the hierarchical analysis of molecular variance analysis (AMOVA), using AMOVA 1.55 (Excoffier et al., 1992). The variance components were tested statistically by nonparametric randomization tests using 1,000 permutations. The Mantel test was used in conjunction with TFPGA software to examine the correlation between genetic and geographic distances (in kilometers) among populations (Miller, 1997).

A Bayesian analysis of ISSR population structure was run on the data set using the program STRUCTURE (Pritchard et al., 2000) to estimate the number of genetic clusters and to evaluate the degree of admixture among them. This method uses a Markov Chain Monte Carlo (MCMC) algorithm to cluster individuals into populations on the basis of multilocus genotype data (Falush et al., 2003). STRUCTURE was run with a burn-in setting of 10,000 followed by 10,000 MCMC iterations using the admixture model with allele frequencies independent among populations. Ten independent runs of $K=1-5$ were done to ensure consistent results. The most likely value for $K$ was calculated with Structure Harvester (Earl and vonHoldt, 2012) by predicting from plots of ad hoc posterior probability models of $\Delta K$. The $\Delta K$ statistic was more appropriate than the highest $\operatorname{Ln} \operatorname{Pr}(X / K)$ method for inferring the population number (Evanno et al., 2005). Once the number of clusters was determined, individuals were assigned to respective populations based on proportional membership $(q)$ for which an arbitrary threshold value of $q=0.90$ was used. Individuals with $q>0.90$ were regarded as members of this cluster, or otherwise as an admixture.

\section{Results}

The 13 selected primers generated 320 ISSR bands in 58 individuals from five populations of $R$. tanguticum, 263 
$(82.2 \%)$ of which were polymorphic (Table 3 ). The bands ranged in size from $200 \mathrm{bp}$ to $2,800 \mathrm{bp}$. The total number of bands varied from 22 (UBC836) to 29 (UBC834), with an average of 24.6 fragments per primer. The percentage of polymorphic bands $(P P B)$ ranged from $42.8 \%$ in the $\mathrm{ZM}$ population to $51.8 \%$ in the DHG population (Table 3). In terms of the presence of alleles within the 320 alleles detected, there were 57 common alleles in the five populations but no unique allele was found for any of the five populations studied.

The measurements of genetic diversity are summarized in Table 3. The value of Nei's gene diversity $(H)$ was 0.2498 and Shannon's Information index $(I)$ was 0.3812 at the species level while at the populations level the corresponding values were 0.1813 and 0.2677 , respectively. The estimates of heterozygosity $\left(H_{B}\right)$ in the full model (which had the lowest DIC, Table 4) based on the Bayesian procedure were generally higher than Nei's gene diversity $(H)$. The expected Bayesian heterozygosity $\left(H_{B}\right)$ was 0.3231 at the species level and 0.2712 at the population level. Among all the populations investigated, the highest and lowest levels of genetic variability occurred in populations DHG $(H=0.1949, I=0.2878)$ and $\mathrm{ZM}(H=0.1671, I=0.2445)$, respectively.

The genetic differentiation among populations $\left(G_{s t}\right)$, estimated by Nei's method, was 0.2742 , which indicated that $27.4 \%$ of the total genetic diversity was distributed among populations, whereas $72.6 \%$ occurred within pop- ulations. Furthermore, the level of gene flow $\left(N_{m}\right)$ was estimated to be 1.3236 individuals per generation between populations, suggesting that gene exchange between populations was high. AMOVA analysis further revealed a similar pattern of genetic differentiation among and within the populations (Table 5). Of the total variation, $23.9 \%$ was attributed to among-population differences, a value much lower than the within-population proportion (76.1\%). AMOVA also showed that differentiation among populations and within populations was significant $(\mathrm{p}<0.0010)$.

The results for $\theta_{B}$ (analogous to Wright's $F_{s t}$ ) estimated by the Bayesian analysis are shown in Table 4. The best model, which had the smallest DIC (3876.31), was the full model, with $\theta_{B}=0.1963$ and $f=0.0886$.

The UPGMA dendrogram, based on Nei's (1978) unbiased genetic distance, is shown in Figure 2. The populations were separated into three groups: HM and QJ formed group I, DHG formed group II and group III contained NX and ZM. The Mantel test revealed no significant correlation between genetic and geographic distances among populations $(r=0.1176, \mathrm{p}=0.3686)$.

The highest peak in $\Delta K$ revealed the best value for $K=3$ indicated that three clusters were detected $(\Delta K=9.10$, Figure $3 \mathrm{~A}$ ). These clusters were entirely consistent with those of the UPGMA clustering results (Figure 3B). Ten individuals were considered admixtures, with $q<0.90$ (Figure 3B).

Table 3 - Genetic diversity indices of the five populations of $R$. tanguticum.

\begin{tabular}{lcccc}
\hline Population & H (SE) & $H_{B}(\mathrm{SD})$ & $\mathrm{I}(\mathrm{SE})$ & $\mathrm{PPB}(\%)$ \\
\hline HM & $0.1885(0.2071)$ & $0.2700(0.0085)$ & $0.2786(0.2955)$ & 51.25 \\
NX & $0.1770(0.2050)$ & $0.2674(0.0085)$ & $0.2618(0.2935)$ & 47.81 \\
ZM & $0.1671(0.2088)$ & $0.2807(0.0096)$ & $0.2445(0.2977)$ & 42.81 \\
DHG & $0.1949(0.2082)$ & $0.2789(0.0080)$ & $0.2878(0.2967)$ & 51.81 \\
QJ & $0.1790(0.2022)$ & $0.2590(0.0082)$ & $0.2659(0.2907)$ & 49.38 \\
Mean at population level & 0.1813 & 0.2712 & 0.2677 & 48.61 \\
Total at species level & 0.2498 & 0.3231 & 0.3812 & 82.19 \\
\hline
\end{tabular}

H - Nei's gene diversity (assuming Hardy-Weinberg equilibrium), $H_{B}$ - expected Bayesian heterozygosity (without assuming Hardy-Weinberg equilibrium); $I$ - Shannon's diversity index; PPB - percentage of polymorphic bands, SE - standard error and SD - standard deviation.

Table 4 - Genetic differentiation calculated among populations of R. tanguticum using different Bayesian approaches.

\begin{tabular}{|c|c|c|c|c|c|c|c|c|c|}
\hline \multirow[t]{2}{*}{ Model } & \multicolumn{4}{|c|}{$\theta_{B}$} & \multicolumn{4}{|c|}{$\mathrm{f}$} & \multirow[t]{2}{*}{ DIC } \\
\hline & Mean & SD & $2.5 \%$ & $97.5 \%$ & Mean & $\mathrm{SD}$ & $2.5 \%$ & $97.5 \%$ & \\
\hline Full model & 0.1963 & 0.0135 & 0.1719 & 0.2244 & 0.0886 & 0.0646 & 0.0051 & 0.0761 & 3876.31 \\
\hline $\mathrm{f}=0$ model & 0.1862 & 0.0108 & 0.1656 & 0.2083 & 0 & - & - & - & 3883.16 \\
\hline$\theta_{B}=0$ & 0 & - & - & - & 0.2801 & 0.0690 & 0.1547 & 0.4241 & 5971.85 \\
\hline f-free model & 0.2490 & 0.0150 & 0.2199 & 0.2784 & 0.4948 & 0.2896 & 0.0257 & 0.9777 & 3980.26 \\
\hline
\end{tabular}

$\theta_{B}$ - analogous to Wright's $F_{s t}, f$ - analogous to Wright's $F_{i s}$, DIC - deviance information criterion and SD - standard deviation. 
Table 5 - Analysis of molecular variance (AMOVA) for wild, cultivated and all populations of R. tanguticum examined in this work.

\begin{tabular}{lcccccc}
\hline Source of variation & d.f. & Sum of squares & Mean squares & Variation components & Total variation (\%) & p value ${ }^{\mathrm{a}}$ \\
\hline Among populations & 4 & 539.36 & 134.84 & 9.21 & 23.91 & $<0.0010$ \\
Within populations & 53 & 1552.93 & 29.30 & 29.30 & 76.09 & $<0.0010$ \\
\hline
\end{tabular}

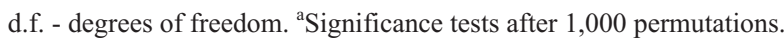

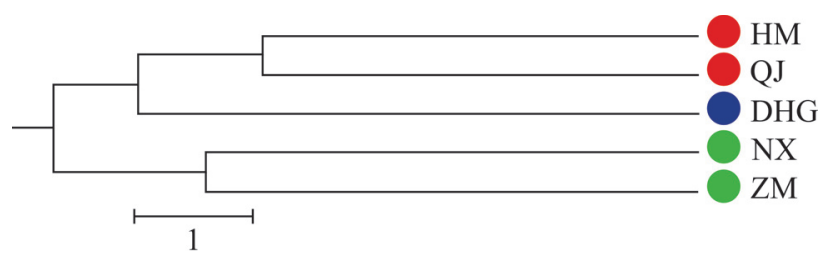

Figure 2 - Dendrogram of cultivated $R$. tanguticum obtained by UPGMA cluster analysis. The three clusters obtained in this analysis are identified by different colored circles.

\section{Discussion}

In this study, the genetic diversity parameter for cultivated populations of $R$. tanguticm $(H=0.1813$, Table 3$)$ was similar to that of wild populations $(H=0.1724)(\mathrm{Hu}$ et al., 2010), as assessed with ISSR markers. However, the genetic diversity was lower than with SSR markers $(H=0.5150)$ in wild $R$. tanguticum (Chen et al., 2009). When compared to those of allied species of Polygonaceae, such as Rheum officinale ( $H=0.1008$ ) (Wang et al., 2012a), Polygonum viviparum $(H=0.1227)$ ( $\mathrm{Lu}$ et al., 2008) and Eriogonum shockleyi var. shockleyi $(H=0.1620)$ (Smith and Bateman, 2002), the genetic diversity in cultivated populations of $R$. tanguticum was high.

The genetic diversity of plant populations is largely influenced by factors such as breeding system, seed dispersal, genetic drift and evolutionary history, as well as life form. Life form and breeding system have highly signifi-

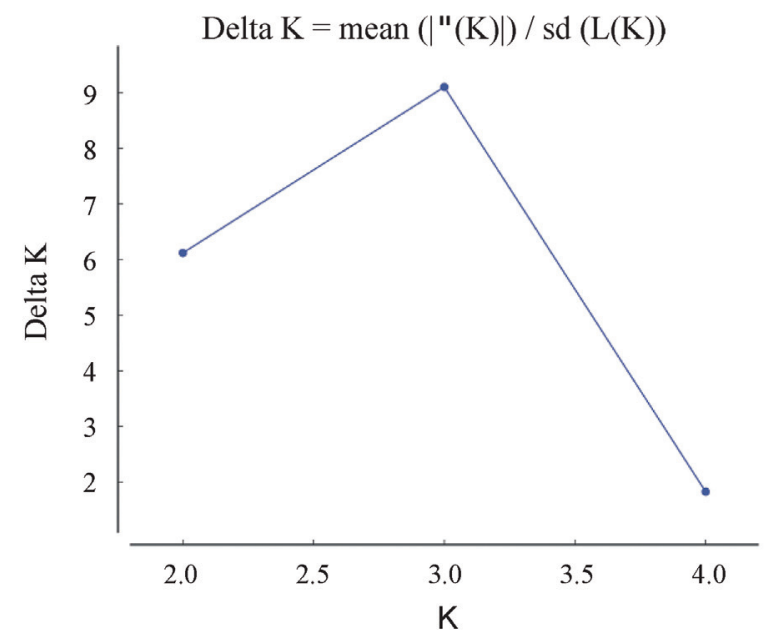

Figure A

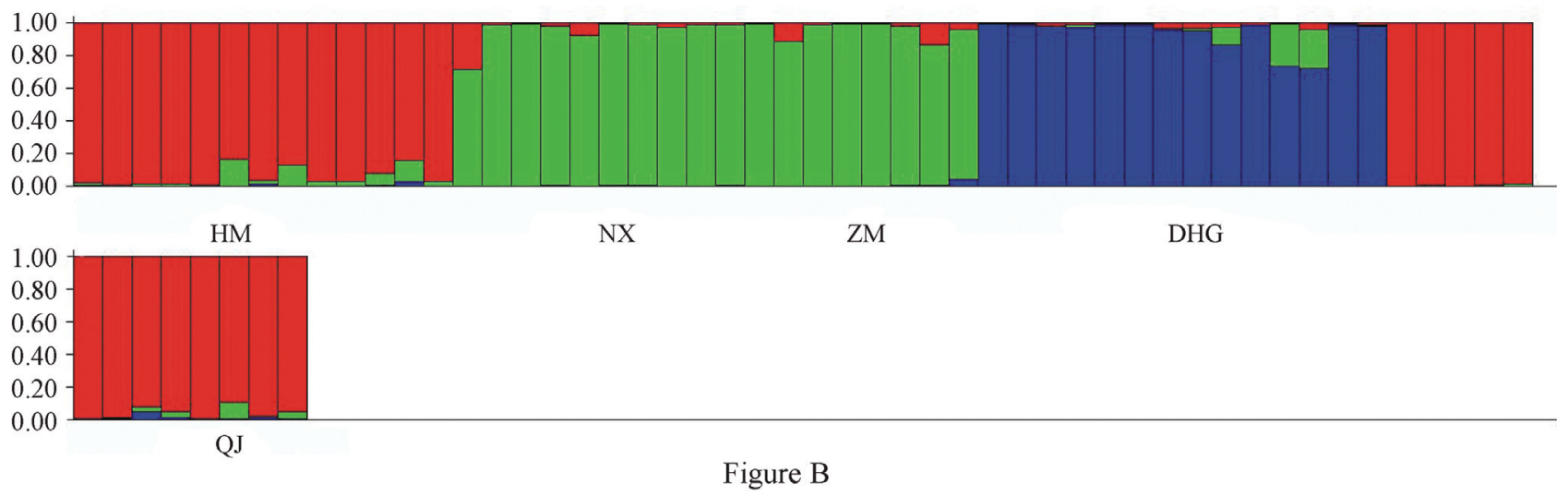

Figure 3 - Bayesian inference of the number of clusters $(K)$ in R. tanguticum. (A) $K$ was estimated from plots of ad hoc posterior probability models of $\Delta K$. (B) Bayesian admixture proportions $(q)$ of individuals of cultivated $R$. tanguticum for $K=3$. Each individual is represented by a single line broken into $K$ colored segments, with lengths proportional to each of the $K$-inferred clusters. 
cant influences on genetic diversity. In general, long-lived and outcrossing species have higher levels of genetic diversity than selfing and clonal plants (Hamrick and Godt, 1996). Bayesian analysis revealed that the inbreeding coefficient $(f=0.0886)$ in $R$. tanguticum was small, a finding that confirmed the outcrossing breeding system of this species. Outcrossing and elevated longevity contribute to the moderately high level of genetic diversity in R. tanguticum. Notably, the current high level of genetic diversity in cultivated $R$. tanguticum may be markedly influenced by the traditional, irregular and sparse agricultural practices of this plant. Traditionally, growers collect and preserve $R$. tanguticum seeds randomly without deliberate selection and mix them together before planting. This practice would preserve more genetic diversity than in wild plants.

$R$. tanguticum has been planted in Qinghai Province since the 1960s. The domestication history is short, there is no artificial selection and cultivation apparently does not influence genetic diversity. In cultivated populations, genetic diversity is partly determined by the way genetic material is passed from one cultivated generation to the next (Miller and Schaal, 2006; Yao et al., 2012). For $R$. tanguticum, seeds are the main genetic material used to establish the cultivated population. Cultivated $R$. tanguticum may have been established from the seeds of a large number of wild progenitors. According to local growers, $R$. tanguticum are collected randomly and mixed together before planting. This was confirmed by the proportional membership $(q)$ calculated with Bayesian analysis. The value of $q$ in 10 individuals was $<0.90$ (Figure 3B), indicating that the origins of these 10 individuals differed from that of other individuals in the same population.

The germplasm can occasionally be dispersed to other places by farmers' relatives or friends. For example, the QJ population was planted by researchers of our institute. The seeds of this population were collected from different places in Golog Prefecture and mixed together. This was confirmed by Bayesian analysis with STRUCTURE software. Figure 3B shows that there were five individuals with a proportional membership $<0.90$. The frequent exchange of seeds further improves the maintenance of genetic diversity (Guo et al., 2007; Yao et al., 2012). Consequently, traditional agricultural practice applied to this plant was another important factor that influenced the abundant genetic diversity of cultivated $R$. tanguticum.

Compared to annual plants, cultivated populations of some perennial plants may harbor a relatively higher percentage of genetic diversity than their wild ancestors (Otero-Arnaiz et al., 2005; Miller and Schaal, 2006; He et al., 2009). Our findings were similar to several other long-lived cultivated plants in which genetic diversity is as high as in the wild relatives (He et al., 2007; Shi et al., 2008). Cultivated $R$. tanguticum had moderate levels of genetic diversity compared with cultivated populations of other endangered Chinese medicinal plants (Table 6) (Wu et al., 2006; Guo et al., 2007; Qiu et al., 2009; Song et al., 2010; Li et al., 2011; Yao et al., 2012), i.e., there was no evidence that a "cultivation bottleneck or founder effect" affected the genetic diversity.

Long-lived and outcrossing species retain most of their genetic variability within populations. In contrast, annual and selfing species allocate most of their genetic variability among populations (Hamrick and Godt, 1996; Nybom, 2004). Our study was consistent with this trend. AMOVA results revealed that in cultivated $R$. tanguticum $76.1 \%$ of the genetic variance was retained within populations while $23.9 \%$ was among populations (Table 5). In the long-lived tree Spondias purpurea, the proportion of genetic variation distributed among populations was greater in cultivated populations than in wild populations, a reflection of the relative amounts of vegetative propagation (Miller and Schaal, 2006). The opposite was observed in cultivated $R$. tanguticum. Cultivated populations $\left(G_{s t}=0.2742\right.$, $\left.\Phi_{s t}=0.239\right)$ had a lower proportion of their genetic variability distributed among populations than wild populations $\left(G_{s t}=0.3585, \Phi_{s t}=0.290\right)($ Hu et al., 2010). Bayesian analysis revealed that the inbreeding coefficient ( $f=0.0886)$ in $R$. tanguticum was small. Based on the records of local growers, these cultivated $R$. tanguticum were grown from seeds rather than being propagated vegeta-

Table 6 - Comparison of genetic diversity of cultivated $R$. tanguticum with other important herbs in cultivated populations.

\begin{tabular}{lccc}
\hline Species & \multicolumn{1}{c}{ Genetic diversity values } & Markers & References \\
\hline R. tanguticum & $P P B_{s}=82.19 \% ; H_{s}=0.2498 ; P P B_{p}=48.61 \% ; H_{p}=0.1813$ & ISSR & Present study \\
Salvia miltiorrhiza & $P P B_{s}=100 \% ; H_{s}=0.1951 ; P P B_{p}=65.00 \% ; H_{p}=0.1591$ & ISSR & Song et al. $(2010)$ \\
Panax ginseng & $P P B_{s}=98.96 \% ; H_{s}=0.2886 ; P P B_{p}=58.01 \% ; H_{p}=0.1890$ & ISSR & Li et al. $(2011)$ \\
Gastrodia elata & $P P B_{s}=61.04 \% ; H_{s}=0.1280 ; P P B_{p}=35.71 \% ; H_{p}=0.1000$ & ISSR & Wu et al. $(2006)$ \\
Corydalis yanhusuo & $P P B_{s}=71.54 \% ; H_{s}=0.1630 ; P P B_{p}=25.32 \% ; H_{p}=0.0940$ & ISSR & Qiu et al. (2009) \\
Codonopsis pilosula & $P P B_{s}=87.23 \% ; H_{s}=0.2992 ; P P B_{p}=73.43 \% ; H_{p}=0.2367$ & RAPD & Guo et al. $(2007)$ \\
Eucommia ulmoides & $P P B_{p}=51.23 \% ; H_{p}=0.1572$ & AFLP & Yao et al. $(2012)$ \\
\hline
\end{tabular}

$H_{p}$ - Nei's gene diversity at the population level, $H_{s}$ - Nei's gene diversity at the species level, $P P B_{p}$ - percentage of polymorphic loci at the population level and $P P B_{s}$ - percentage of polymorphic loci at the species level. 
tively. Thus, the mating system was outcrossing in cultivated populations, the same as in wild populations.

STRUCTURE analysis showed that 10 individuals were admixtures with $q<0.90$ (Figure 3B), indicating that cultivated $R$. tangutium had been introduced to cultivation from the seeds of a large number of wild progenitors. The planting records revealed that the germplasm had been dispersed to other places by the growers, with mixing and exchanging of seeds before planting. The frequent exchange of seeds enhanced the gene flow from wild populations into cultivated populations. Subsequently, the genetic variation within populations increased while that among populations decreased in cultivated populations.

The findings of this study indicate that $R$. tanguticum has maintained a relatively high level of genetic diversity in cultivated populations that may play a crucial role in conserving this species in the face of declining wild populations. A short cultivation history and no artificial selection do not decrease the genetic diversity of $R$. tanguticum and no special cultivar is formed. The primitive agricultural practices, i.e., random collecting, preserving and planting of seeds without deliberate selection may be an effective way of maintaining and conserving the gene pools of wild plants (Guo et al., 2007; Song et al., 2010). Furthermore, given that the genetic diversity of the QJ cultivated populations of $R$. tanguticum was relatively higher than that of wild populations at the population level, the current planting at this site can be seen as a preliminary step for ex situ conservation. Additionally, other effective approaches, such as Good Agricultural Practice (GAP), also need be adopted to meet the market demand and achieve future sustainable use of this medicinal plant.

\section{Acknowledgments}

This work was supported by the National Key Technology R\&D Program of China (grant no. 2012BAC08B04), the National Nature Science Foundation of China (grant no. 31200245) and the West Light Foundation of the Chinese Academy of Sciences for Doctors (2011).

\section{References}

Che G, Li Y, Wang L, Zhou G, Suo Y and Chen G (2006) Seasonal change of anthroquinone content in cultivated Rheum tanguticum. Acta Bot Boreal-Occident Sin 26:2378-2382.

Chen F, Wang A, Chen K, Wan D and Liu J (2009) Genetic diversity and population structure of the endangered and medically important Rheum tanguticum (Polygonaceae) revealed by SSR markers. Biochem Syst Ecol 37:613-621.

Chen DX, Li LY, Zhang X, Wang Y and Zhang Z (2013) Genetic diversity in wild Dipsacus chinensis populations from China based on ISSR markers. Genet Mol Res 12:1205-1213.

Chinese Pharmacopeia Commission (2010) Pharmacopoeia of the People's Republic of China. vol 1. China Medical Science Press, Beijing, pp 22-23.
Doyle J and Doyle J (1987) A rapid DNA isolation procedure for small quantities of fresh leaf tissue. Phytochem Bull 19:1115 .

Evanno G, Regnaut S and Goudet J (2005) Detecting the number of clusters of individuals using the software STRUCTURE: A simulation study. Mol Ecol 14:2611-2620.

Excoffier L, Smouse P and Quattro J (1992) Analysis of molecular variance inferred from metric distances among DNA haplotypes: Application to human mitochondrial DNA restriction data. Genetics 131:479-491.

Falush D, Stephens M and Pritchard JK (2003) Inference of population structure using multilocus genotype data: Linked loci and correlated allele frequencies. Genetics 164:1567-1587.

Guo HB, Lu BR, Wu QH, Chen JK and Zhou TS (2007) Abundant genetic diversity in cultivated Codonopsis pilosula populations revealed by RAPD polymorphisms. Genet Resour Crop Evol 54:917-924.

Hamrick JL and Godt MJW (1996) Effects of life history traits on genetic diversity in plant species. Philos Trans R Soc Lond B Biol Sci 351:1291-1298.

He J, Wang H, Li DZ and Chen SF (2007) Genetic diversity of Paris polyphylla var. yunnanensis, a traditional Chinese medicinal herb, detected by ISSR markers. Planta Med 73:1316-1321.

He JS, Chen L, Si Y, Huang B, Ban XQ and Wang YW (2009) Population structure and genetic diversity distribution in wild and cultivated populations of the traditional Chinese medicinal plant Magnolia officinalis subsp biloba (Magnoliaceae). Genetica 135:233-243.

Holsinger KE and Lewis PO (2003) HICKORY: A package for analysis of population genetic data Ver 1.1. Department of Ecology and Evolutionary Biology, University of Connecticut, Storrs, USA.

Holsinger KE and Wallace LE (2004) Bayesian approaches for the analysis of population genetic structure: An example from Platanthera leucophaea (Orchidaceae). Mol Ecol 13:887-894.

Holsinger KE, Lewis PO and Dey DK (2002) A Bayesian approach to inferring population structure from dominant markers. Mol Ecol 11:1157-1164.

Hu Y, Wang L, Xie X, Yang J, Li Y and Zhang H (2010) Genetic diversity of wild populations of Rheum tanguticum endemic to China as revealed by ISSR analysis. Biochem Syst Ecol 38:264-274.

Komatsu K, Nagayama Y, Tanaka K, Ling Y, Basnet P and Meselhy MR (2006) Development of a high performance liquid chromatographic method for systematic quantitative analysis of chemical constituents in rhubarb. Chem Pharm Bull (Tokyo) 54:941-947.

Kumchai J, Wei YC, Lee CY, Chen FC and Chin SW (2013) Production of interspecific hybrids between commercial cultivars of the eggplant (Solanum melongena L.) and its wild relative $S$. torvum. Gen Mol Res 12:755-764.

Li A (2003) Flora of China 5. Science Press, Beijing, 444 pp.

Li M, Li LX, Liu Y and Liu Y (2006) Study survey on rhubarb in recent years. World Sci Technol-Mod Tradit Chin Med Mat Med 8:34-39.

Li S, Li J, Yang XL, Cheng Z and Zhang WJ (2011) Genetic diversity and differentiation of cultivated ginseng (Panax ginseng C. A. Meyer) populations in north-east China revealed by 
inter-simple sequence repeat (SSR) markers. Genet Resour Crop Evol 58:815-824.

Liu S (1997) Flora of Qinghai, vol 2. Qinghai People's Publishing House, Xining, $463 \mathrm{pp}$.

Lu J, Yang X and Ma R (2008) Genetic diversity of clonal plant Polygonum viviparum based RAPD in eastern QinghaiTibet Plateau of China. J Northwest Normal University (Nat Sci) 44:66-72.

McDermott J and McDonald B (1993) Gene flow in plant pathosystems. Annu Rev Phytopathol 31:353-373.

Miller AJ and Schaal BA (2006) Domestication and the distribution of genetic variation in wild and cultivated populations of the Mesoamerican fruit tree Spondias purpurea L. (Anacardiaceae). Mol Ecol 15:1467-1480.

Nei M (1973) Analysis of gene diversity in subdivided populations. Proc Natl Acad Sci USA 70:3321-3323.

Nei M (1978) Estimation of average heterozygosity and genetic distance from a small number of individuals. Genetics 89:583-590.

Nybom H (2004) Comparison of different nuclear DNA markers for estimating intraspecific genetic diversity in plants. Mol Ecol 13:1143-1155.

Otero-Arnaiz A, Casas A, Hamrick JL and Cruse-Sanders J (2005) Genetic variation and evolution of Polaskia chichipe (Cactaceae) under domestication in the Tehuacan Valley, central Mexico. Mol Ecol 14:1603-1611.

Pritchard JK, Stephens M and Donnelly P (2000) Inference of population structure using multilocus genotype data. Genetics 155:945-959.

Qiu YX, Zong M, Yao Y, Chen BL, Zhou XL, Chen ZL and Fu CX (2009) Genetic variation in wild and cultivated Rhizoma Corydalis revealed by ISSRs markers. Planta Med 75:94-98.

Rohlf F (2000) NTSYS-pc: Numerical taxonomy and multivariate analysis system, ver 2.1. New York, NY.

Shi W, Yang CF, Chen JM and Guo YH (2008) Genetic variation among wild and cultivated populations of the Chinese medicinal plant Coptis chinensis (Ranunculaceae). Plant Biol 10:485-491.

Smith JF and Bateman TA (2002) Genetic differentiation of rare and common varieties of Eriogonum shockleyi (Polygonaceae) in Idaho using ISSR variability. West N Am Nat 62:316-326.

Song Z, Li X, Wang H and Wang J (2010) Genetic diversity and population structure of Salvia miltiorrhiza Bge in China revealed by ISSR and SRAP. Genetica 138:241-249.

Spiegelhalter DJ, Best NG, Carlin BR and van der Linde A (2002) Bayesian measures of model complexity and fit. J R Stat Soc Series B-Stat Methodol 64:583-616.

Tacuatia LO, Eggers L, Kaltchuk-Santos E and Souza-Chies TT (2012) Population genetic structure of Sisyrinchium micranthum Cav. (Iridaceae) in Itapua State Park, southern Brazil. Genet Mol Biol 35:99-105.

Tero N, Aspi J, Siikamäki P, Jäkäläniemi A and Tuomi J (2003) Genetic structure and gene flow in a metapopulation of an endangered plant species, Silene tatarica. Mol Ecol 12:2073-2085.

The People's Government of Qinghai Province (2009) List of key protected wild plants of Qinghai Province. Qinghai Prataculture 18:50-51.

Thriveni H, Sumangala R, Shivaprakash K, Ravikanth G, Vasudeva R and Babu HR (2014) Genetic structure and diversity of Coscinium fenestratum: A critically endangered liana of Western Ghats, India. Plant Syst Evol 300:403-413.

VanMen C, Jang YS, Zhu HM, Lee JH, Trung TN, Ngoc TM, Kim YH and Kang JS (2012) Chemical-based species classification of rhubarb using simultaneous determination of five bioactive substances by HPLC and LDA analysis. Phytochem Anal 23:359-364.

Verma S and Rana TS (2013) Genetic relationships among wild and cultivated accessions of curry leaf plant (Murraya koenigii (L.) Spreng.), as revealed by DNA fingerprinting Methods Mol Biotechnol 53:139-149.

Wang XM (2010) Optimization of DNA isolation, ISSR-PCR system and primers screening of genuine species of rhubarb, an important herbal medicine in China. J Med Plants Res 4:904-908.

Wang X and Ren Y (2009) Rheum tanguticum, an endangered medicinal plant endemic to China. J Med Plants Res 3:11951203.

Wang XM, Hou XQ, Zhang YQ, Yang R, Feng SF, Li Y and Ren Y (2012a) Genetic diversity of the endemic and medicinally important plant Rheum officinale as revealed by inter-simple sequence repeat (ISSR) markers. Int J Mol Sci 13:39003915.

Wang X, Yang R, Feng S, Hou X, Zhang Y, Li Y and Ren Y (2012b) Genetic variation in Rheum palmatum and Rheum tanguticum (Polygonaceae), two medicinally and endemic species in China using ISSR markers. PLoS ONE 7:e51667.

Wu HF, Li Z and Huang H (2006) Genetic differentiation among natural populations of Gastrodia elata (Orchidaceae) in Hubei and germplasm assessment of the cultivated populations. Biodiv Sci 14:315-326.

Yang M, Zhang D, Zheng J and Liu J (2001) Pollen morphology and its systematic and ecological significance in Rheum (Polygonaceae) from China. Nord J Bot 21:411-418.

Yang YC (1991) Tibetan Medicine. Qinghai People's Press, Xining, $670 \mathrm{pp}$.

Yao X, Deng J and Huang H (2012) Genetic diversity in Eucommia ulmoides (Eucommiaceae), an endangered traditional Chinese medicinal plant. Conserv Genet 13:14991507.

Yeh F, Yang R and Boyle T (1999) POPGENE version 1.32. Microsoft Window-based freeware for population genetic analysis. Molecular Biology and Biotechnology Center, University of Alberta, Canada.

Zhang XF (2004) Xining rhubarb. Science Press of Shanxi, Xi'an, $168 \mathrm{pp}$.

Zhang D, Chen S and Gao Q (2007) Patterns of genetic variation in Swertia przewalskii, an endangered endemic species of the Qinghai-Tibet Plateau. Biochem Genet 45:33-50.

Zietkiewicz E, Rafalski A and Labuda D (1994) Genome fingerprinting by simple sequence repeat (SSR)-anchored polymerase chain-reaction amplification. Genomics 20:176-183.

\section{Internet Resources}

Primer Sets of University of British Columbia (UBC) set no. 9, http://www.michaelsmith.ubc.ca/services/NAPS/Primer_Sets/Primers_Oct2006.pdf(October 5, 2006).

Earl DA and von Holdt BM (2012) STRUCTURE HARVESTER: A website and program for visualizing STRUCTURE output 
and implementing the Evanno method. Conserv Genet Res 4:359-361. http://taylor0.biology.ucla.edu/structureHarvester/ (November 1, 2012).

Miller M (1997) Tools for population genetic analyses (TFPGA) 1.3: A Windows program for the analysis of allozyme and molecular population genetic data. Department of Biological Sciences, Northern Arizona University, Arizona, USA. http://www.marksgeneticsoftware.net/_vti_bin/shtml.exe/tf pga.htm (March 5, 2009).

Associate Editor: Everaldo Gonçalves de Barros

License information: This is an open-access article distributed under the terms of the Creative Commons Attribution License, which permits unrestricted use, distribution, and reproduction in any medium, provided the original work is properly cited. 